\title{
The Effect of Community Interventions on Alcohol-related Assault in Geelong, Australia
}

\author{
Peter G. Miller ${ }^{1, *}$, Anders L. Sønderlund ${ }^{1}$, Kerri Coomber ${ }^{1}$, Darren Palmer $^{2}$, Jennifer Tindall ${ }^{3}$, \\ Karen Gillham ${ }^{3}$ and John Wiggers ${ }^{3,4}$ \\ ${ }^{1}$ Deakin University, School of Psychology, Geelong, Victoria 3220, Australia \\ ${ }^{2}$ Deakin University, School of History, Heritage and Society, Geelong, Victoria 3220, Australia \\ ${ }^{3}$ Hunter New England Population Health, Newcastle, New South Wales 2300, Australia \\ ${ }^{4}$ School of Medicine and Public Health, University of Newcastle, Newcastle, New South Wales 2300, Australia
}

\begin{abstract}
Alcohol has consistently been demonstrated to increase levels of aggression and violence, particularly in late night licensed venues. Since 2005, the City of Geelong in Australia has implemented a substantial number of interventions to reduce alcohol related violence, including a liquor accord, increased police surveillance, ID scanners, CCTV, a radio network and an alcohol industry sponsored social marketing campaign. The aim of the current study is to assess the individual and collective impact of community interventions on indicators of alcohol-related assaults in the Geelong region. This paper reports stage one findings from the Dealing with Alcohol-related problems in the Night-time Economy project (DANTE) and specifically examines assault rate data from both emergency department presentations, ICD-10 classification codes, and police records of assaults. None of the interventions were associated with reductions in alcohol-related assault or intoxication in Geelong, either individually or when combined. However, the alcohol industry sponsored social marketing campaign 'Just Think' was associated with an increase in assault rates. Community level interventions appeared to have had little effect on assault rates during high alcohol times. It is also possible that social marketing campaigns without practical strategies are associated with increased assault rates. The findings also raise questions about whether interventions should be targeted at reducing whole-of-community alcohol consumption.
\end{abstract}

Keywords: Assault, alcohol, community interventions, violence, venues.

\section{INTRODUCTION}

Alcohol has consistently been demonstrated to increase levels of aggression and violence, particularly in late night licensed venues. Further, alcohol has been associated with domestic violence (Klostermann and Fals-Stewart, 2006; Salcedo and Carvalho, 2005), sexual assault (Abbey and Ortiz, 2008; Abbey et al., 2002), and assault (Finney, 2004; Ingemann-Hansen and Brink, 2004). In Australia, a substantial proportion of the problems associated with alcohol and interpersonal violence arise in or around licensed premises in the night-time economy (NTE; Collins and Lapsley, 2008; Chikritzhs and Stockwell, 2002; Rowe et al., 2010) and strong links between alcohol outlet density and violence have been documented (Livingston, 2008; Livingston et al., 2007).

The most effective interventions for reducing alcoholrelated harm (including violence) have centred on federal and state-wide control policies reducing access to alcohol through increased prices, reduced trading hours and reduced

*Address correspondence to this author at the Deakin University, School of Psychology Geelong Waterfront Campus Locked Bag 20000, Geelong, Vic, 3220, Australia; Tel: +61 35227 8138; Cell: +61 429024 844;

Fax: +61 (03) 52 278621; E-mail: petermiller.mail@gmail.com number of outlets (Babor et al., 2010; Miller et al., 2010). At a community-level, the main approaches shown to be effective in reducing alcohol-related violence and injury revolve around enforcement of licensing laws (Babor et al., 2010). The most prominent examples include the Alcohol Linking Program (Wiggers et al., 2004), the Queensland Safety Action Project (Hauritz and Homel, 1998), and the Swedish Stockholm prevents alcohol and drug-problems (STAD; Wallin et al., 2005) which have all been shown to be relatively successful. In contrast, other community level interventions have not been as successful in reducing harm. These include alcohol-interventions with licensees, community alcohol accords, and community action projects that include strategies such as banned patron lists; agreed levels of security surveillance; the implementation of ID scanners in highrisk licensed premises; use of two-way radios by security staff, agreements that police be contacted immediately upon the identification of problem patrons, and alcohol awareness campaigns (Graham and Homel, 2008). They can however be effective in bringing stakeholders together. Notwithstanding the lack of supportive evidence, such strategies are commonly applied at the local level (Graham and Homel, 2008).

In the context of such evidence and practice, the current study investigated the effect of a number of interventions in 
the city of Geelong, Australia. Geelong is unique when it comes to dealing with alcohol-related problems as it is one of the first cities in the world to implement a liquor accord (1991). The Geelong Liquor Accord (GLA) consists of police, licensees and council representatives meeting regularly to discuss and agree on strategies for dealing with alcoholrelated problems (Rumbold et al., 1998). A study of the GLA found an initial reduction in alcohol-related harm (Rumbold et al., 1998). While the exact make-up of the GLA has changed over time, it continues today (see http://www.webcitation.org/5qfKjLHFJ), and consists of a number of principles and actions agreed to by all participating stakeholders. While this accord reflects a general sense of co-operation in the aim to reduce alcohol-related problems in the NTE, a number of venues continue to operate outside the accord regulations, and disagreement among participants still exists on some issues.

The local history of targeting alcohol-related harms in Geelong, has since 1991 precipitated the trials of over 25 different local interventions focussed on reducing alcoholrelated violence. One intervention that was a direct outcome of the Liquor Accord involved the installation of a six camera CCTV network in 2003 which had expanded to include 24 cameras by the end of 2009. This network operates in conjunction with the Night-Watch Radio Program (NWRP). This was introduced in 2007 and connects security staff in licensed venues by two-way radios with city security camera operators, street cleaners, taxi rank staff, nearby fast food venues and police.

An additional outcome of the GLA was the implementation of ID-scanners in 2007 in every late night (post 1am) licensed venue in Geelong. Scanner technology varies from simple image recording to machines that can match ID images to photographs taken at the same time. Such scanners are also programmed to recognise 154 different types of ID from around the world, and can pick-out fake or altered IDs. In theory, every patron entering a venue is scanned, as well as recorded on CCTV, thus giving a record of when the individual entered the venue and how they were dressed as well as all of their personal identification details.

In 2008, with no involvement from the GLA or local Community Safety Committee, the 'Just Think' campaign was launched by the local tabloid newspaper, the Geelong Advertiser. This media campaign was funded by the alcohol industry social aspect/public relations organisation, Drinkwise. The campaign used football stars and other celebrities to endorse the message, 'we're not saying don't drink, we're saying just think', and further featured the pictures of battered victims alongside professional footballers. Just Think was run sporadically and determining an effect would thus involve identifying and controlling for a substantial number of confounding factors (Agostinelli and Grube, 2002; Austin, 2000).

Finally, Victoria Police also initiated Operation Nightlife 1 in 2007 which centred on maximum police visibility and increased man-power during high-risk hours (weekend evenings and early mornings).
Overall, although these interventions (see Table $\mathbf{1}$ for a summary) have been implemented in good faith, few of them were based on the available evidence, with none of them having been empirically evaluated since implementation either individually or collectively. Most of these interventions continue to run in 2011, although the Just Think campaign has not been active since September 2010. In the context of the extensive activity to reduce alcohol-related harms in Geelong over an extended period, the current study was undertaken to assess the individual and collective impact of community interventions on indicators of alcohol-related assaults in the Geelong region of Victoria, Australia.

\section{METHOD}

\section{The Context}

Geelong is a city of approximately 205,000 people with a growth rate of $1.1 \%$ per annum. Located 70 kilometres from the state capital, Melbourne, it is both a regional centre and effectively a suburb of Melbourne, with over 11,000 people commuting to the capital every day.

\section{Data}

This paper reports stage one findings from the Dealing with Alcohol-related problems in the Night-time Economy project (DANTE) relating to assaults recorded by local police and hospitals within the postcode area of 3220, Geelong. Ethics permission to analyse hospital emergency department (ED) and Victoria Police data was obtained from the Deakin University Human Ethics Committee prior to commencement of the study (ethics approval number HEAG-H 16_09).

Further to this, Victoria Police assault data for the dates of 1 July, 2004 to 31 May, 2009 were obtained. Victoria Police data analysed in the report here refer to incidents (rather than number of people involved per incident) and report on all assault codes, including sexual assaults, recorded in the Victoria Police Law Enforcement Assistance Program (LEAP) database. Assault includes indictable and summary assault offences such as intentionally/recklessly causing injury, making threats to kill, reckless conduct endangering life/serious injury, unlawful assault, assault police (serious and summary) assault with weapon/instrument, and discharge missile/stone to injure/danger; (Victoria Police, 2011).

Lastly, ED ICD-10 codes pertaining to alcohol-related assault including anyone over 14 years old), and any X85 to Y09 or Y87.1 (sequelae of assault codes) for the period July 1, 1999 through January 31, 2008 were analysed. This data for the study was obtained from Barwon Health Geelong hospital records. Keyword searches of the triage records targeting cases of alcohol-related violence were manually conducted by five coders. This method has been shown to be effective within past research (Indig et al., 2008).

The data were further aggregated to include only those incidents which occurred within the 'high alcohol hours' (HAH) of 8pm-6am Friday to Sunday morning (Laslett et al., 2007). This resulted in a total of 536 ED-cases from the EDkeyword data, 822 cases from ED-ICD data, and 1688 from 
the Victoria police data. Assaults occurring within the Geelong Local Government Area are analysed here, as they are comparable to the numbers of people ultimately attending the emergency department. Although this does have the limitation of not being specific to nightclub districts, it relates to alcohol-related assault across the community and any reductions in assaults in the entertainment district could be expected to impact on the overall trends.

Lastly, demographic data including age, gender and postcode of residence was collected for ED attendances. The data supplied by Victoria Police lacked sufficient detail to generate similar demographics

\section{Analysis}

Analysis was conducted in two stages. Firstly, descriptive statistics including assault-rates by year were presented in time-line graphs for the dates of the obtained data. Secondly, pre- to post-intervention effects were assessed using linear regression analysis. Alcohol-related assault rates were aggregated by week, and thus consisted of 214 time points through the time-frame of 1 July, 2005 to 31 July, 2009 for the ED-keyword data, and 254 time points through the timeframe of 1 July, 2004 to 31 May, 2009 for the police data. Each intervention was represented by a dichotomous dummy variable with values pre-intervention (0) and postintervention (1).

While a time-series analysis of the data would have been ideal and probably more direct than regression analysis, a fundamental assumption of this technique is the presence of serial autocorrelation and data-stationarity. Durbin-Watson tests, however, indicated no significant autocorrelation in the ED data $\left(d=1.866>d_{u, 0.05}=1.806\right)$ or in the Victoria Police data $\left(d=2.116>d_{u, 0.05}=1.780\right)$, and stationarity was unobtainable through differencing or log-transformations. . For these reasons, a time-series approach was unfeasible. However, multiple regression analyses can determine whether assault-rates post-intervention were significantly different to the rates pre-intervention.

\section{RESULTS}

\section{Geelong Hospital ED Data}

\section{Demographics}

For the ED keyword data-set, the age-range spanned from 15 to 77 with a mean age of $27(\mathrm{SD}=9.5)$, and a mode age of 20. The age-group 15-24 comprised over half of the entire set of instances with $56.7 \%(n=304)$ of this age. Males were far more frequently involved in assault cases than were females, with $77.8 \%(n=417)$ of triage presentations being male. The proportion of male/female offenders and ED attendees remained relatively stable over time.

For the ED-ICD data-set, the age-range spanned from 13 to 78 with a mean age of 27 (SD=9.9), and a mode age of 20 . The age-group 15-24 comprised over half of the entire set of instances with $50.2 \%(n=267)$ of this age. Males were far more frequently involved in assault cases than were females, with $75.4 \%(n=438)$ of triage presentations being male.

\section{Alcohol-related Assaults}

According to triage-keyword records, the vast majority (73.7\%: 486 of 659) of alcohol-related assaults took place on weekends between Friday evening and Sunday morning. Further, 48.4\% ( $n=235)$ of weekend cases occurred on Sundays mornings alone, with $32.2 \%(n=212)$ of these cases presenting at triage on Sunday mornings between 12am and 6am - making this time of the week the most high-risk in terms of alcohol-related assaults presenting at ED. Findings from ICD data are very similar to those seen in the keyword searches.

\section{Victoria Police Data}

Utilising data from Victoria Police for the Geelong postcode, the frequency of assaults for time of day and day of week for peak times (see Fig. 1) and month were calculated. As shown, the highest frequency of assaults occurred during the hours of midnight and 1:00am, with assault rates remaining relatively high until 4:00am. Sunday mornings had the

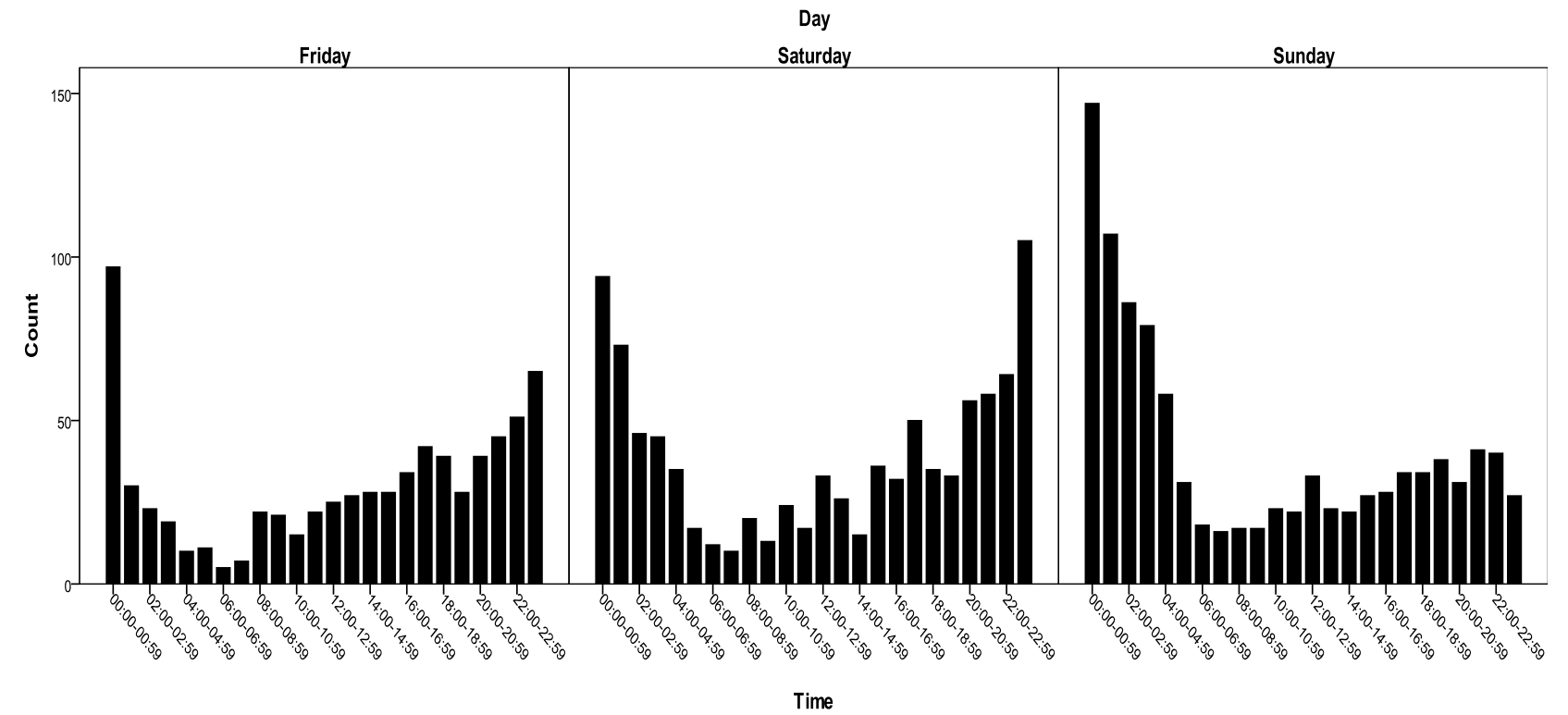

Fig. (1). Victoria Police arrests by time of day during high alcohol times in Geelong. 
most assaults, occurring primarily during the high assault rate hours between midnight and 4am. Lastly, January was the month with the highest number of assaults.

\section{Alcohol-related Assault Rates by Year}

Fig. (2) below demonstrates the frequency of alcoholrelated assaults, taken from Geelong police data, and ED keyword and ED-ICD10 data, with reference lines for each of the four interventions implemented in 2007, 2008 and 2009. Data is presented quarterly as it demonstrates more robust trends and eliminates monthly fluctuations which often tend to obscure overall patterns. Fig. (3) demonstrates these rates at high-alcohol hours, using ED keyword data and police data. Visually, none of the interventions appear to have had a lasting, if any, impact at all on assault rates. Although Operation Nightlife 2 precipitates a slight decrease in June-July, 2009, there is not enough data past the implemen-

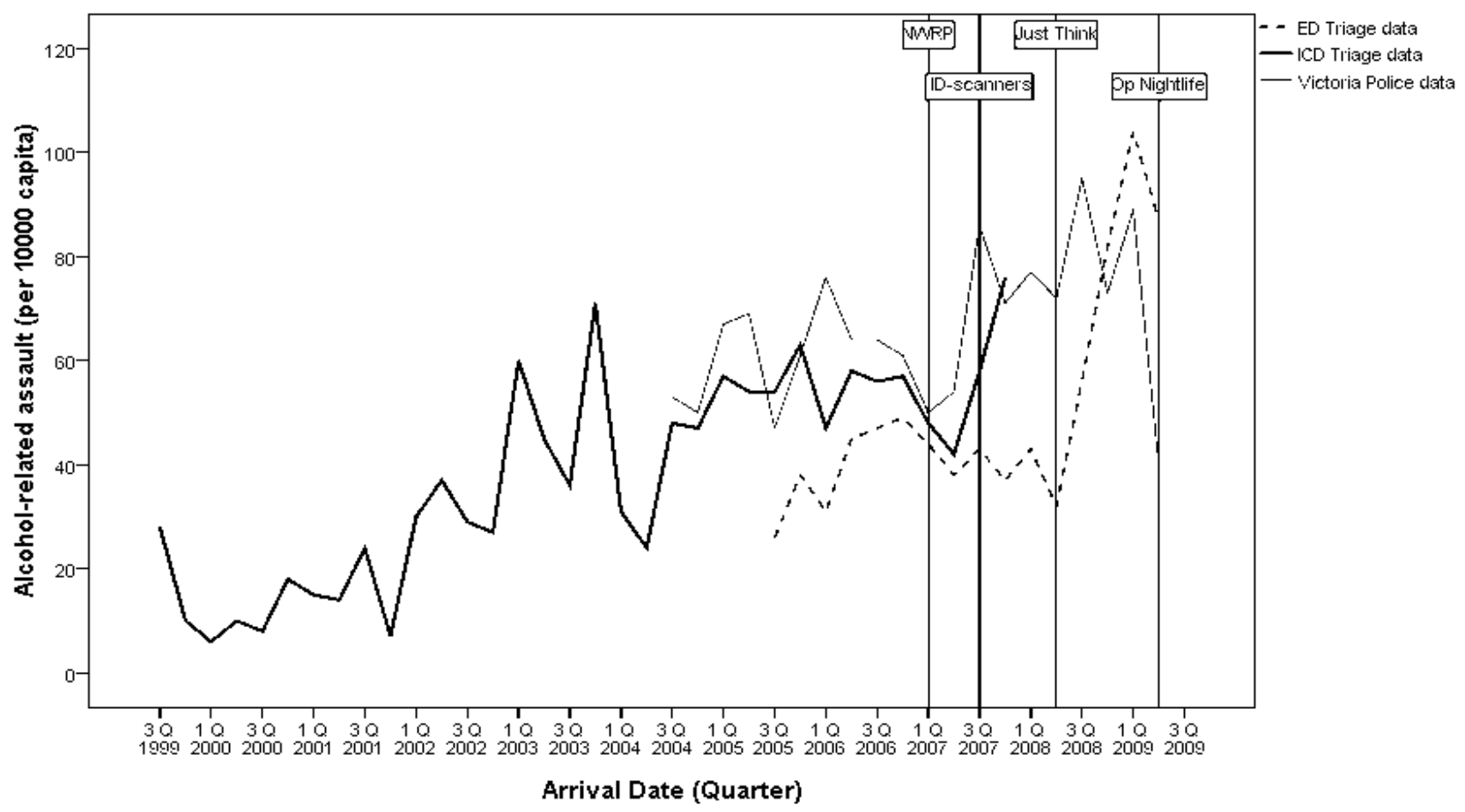

Fig. (2). Alcohol-related assault rates (per 10,000) by quarter and year (all hours) in Geelong.

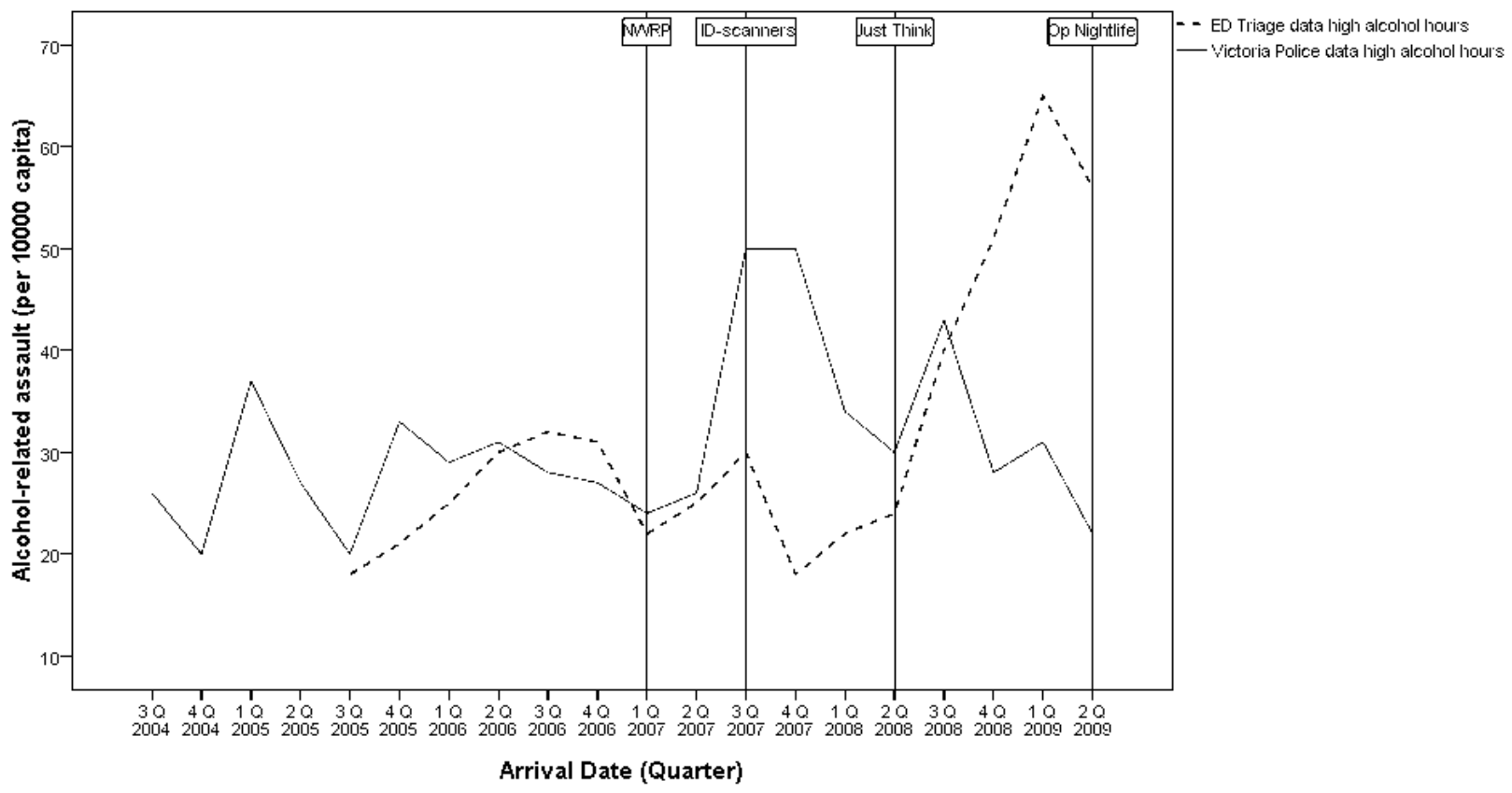

Fig. (3). Alcohol-related assault rates (per 10,000) by quarter and year (high alcohol hours) in Geelong. 
tation date to make any judgements about the continuation of such an effect.

\section{Regression Analysis}

Linear regression analyses of the data were conducted to help ascertain the impact of the implemented interventions (IVs) on alcohol-related assault rates (DV). IVs were represented by dummy variables coded 0 (pre-intervention) and 1 (post-intervention). All analysis was performed using SPSS 17.

An examination of $z$-scores (critical value \pm 3.29 ) revealed four outliers for the ED-data and 11 for the police data. The outliers were recoded to the second-most extreme value. Assumptions of linearity and homoscedasticity of residuals were met. As assault-frequency for both data-pools was positively skewed (ED-data: skewness=.675, $S E=.340$; police data: skewness=.745, $S E=.311$ ) square root transformations were undertaken to normalise the distributions for the NWRP and ID-scanner IVs, while a logarithmic transformation was required for the Just Think IV. The distribution for the Operation Nightlife 2 could not be normalised. In addition, there were only four time points, i.e., weeks, of post-intervention data for Operation Nightlife 2. For these two reasons the Operation Nightlife 2 intervention was not included in the analyses.

\section{ED-data Regression}

Two separate regression analyses were conducted on the triage data, the first to examine the impact of NWRP and ID- scanner interventions, and the second to examine the impact of the Just Think campaign. These regression models used the weekly aggregated data for high-alcohol hours (HAH). The first regression model for the ED-data revealed a significant $R^{2}=.04$ ( $R^{2}$ adjusted $\left.=.03\right), F_{(4,212)}=3.76, p<.025$ for the NWRP and ID-scanner IVs. Overall this model thus explained only $4 \%$ (3\% adjusted) of the variability in alcoholrelated assault rates. The second regression model for the Just Think campaign generated a significant $R^{2}=.17\left(R^{2}\right.$ adjusted $=.17), F_{(4,212)}=38.87, p<.000$, thus accounting for $17 \%$ of the variability in alcohol-related assaults. As indicated in Table 1, only the Just Think campaign generated a significant, unique association with increased rates of alcoholrelated assault.

\section{Police-data Regression}

The police-data regression generated no significant results for the overall regression model or any of the individual IVs. There were no significant changes in alcohol-related assault rates over time associated with the NWRP, IDscanners or the Just Think campaign (see Table 2).

\section{DISCUSSION}

Alcohol-related assault ED presentations in the Geelong region have risen consistently since 2005. Further, the rate of assaults in Geelong in the current study is similar to the Victorian average, and the observed increases in assaults match trends observed state-wide as well (Livingston et al., 2010). Importantly, none of the implemented interventions in Geelong have been associated with any measurable decrease in

Table 1. Description of Alcohol-related Interventions Implemented in Geelong, Victoria

\begin{tabular}{|c|c|c|}
\hline Name of intervention & Date implemented & Description \\
\hline Night-Watch Radio Program & Mar 2007 & Connection of security staff via radio with relevant personnel \\
\hline ID-Scanners & Oct 2007 & Matches ID images to photographs to detect fake IDs \\
\hline Just Think & Jun 2008 & Local celebrities endorsing safe drinking patterns \\
\hline Operation Nightlife 1 & Jan 2007 & Maximum police visibility during high-risk hours \\
\hline Operation Nightlife 2 & Jun 2009 & Improved radio contact between police and licensees \\
\hline Safe Streets Taskforce & Dec 2008 & Increase police visibility \\
\hline Operation Razon & Apr 2008 onwards & Undercover police at licensed venues \\
\hline
\end{tabular}

Table 2. Linear Regression Analyses of Pre- to post-intervention Data

\begin{tabular}{|c|c|c|c|c|c|c|}
\hline & \multicolumn{3}{|c|}{ Police-data } & \multicolumn{3}{|c|}{ ED-data } \\
\hline Intervention (IV) & B & $\beta$ & $\mathrm{sr}^{2}$ & B & $\beta$ & $\mathrm{sr}^{2}$ \\
\hline Night Watch Radio Program & .11 & .08 & .22 & .01 & .01 & .07 \\
\hline ID-scanners & .10 & .07 & .20 & .26 & .18 & .35 \\
\hline \multicolumn{7}{|c|}{ Second regression model } \\
\hline Just Think Campaign & -.01 & -.00 & .00 & .52 & .41 & $6.4^{*}$ \\
\hline
\end{tabular}

$* p<.001$; ED-data $d f=210$; Police-data $d f=251$ 
alcohol-related injury rates. While the 'Just Think' social marketing campaign was associated with increased ED presentations associated with alcohol use, causal attributions cannot be made in this context. While trying to determine the individual impact of any of these interventions was relatively difficult, we were fortunate that most of them were implemented in intervals of at least 6 months between each other. Such periods in between interventions has the potential to allow for secondary data to reflect any consequent changes in assault rates. However, it is possible that some effects might not occur immediately after implementation, and it is possible that some interventions may have a cumulative impact.

The reasons underlying the absence of any obvious change being associated with these interventions are open to speculation. The most likely explanation is that none of the interventions are consistent with evidence-based interventions, such as those which address total alcohol consumption (e.g. excise taxation on alcohol) have consistently been found to be the most - if not only - effective measures for reducing alcohol-related violence (Anderson et al., 2009; Babor et al., 2003; Babor et al., 2010; Graham and Homel, 2008).

It is possible that the highly publicised examples of alcohol-related violence frequently used for the Just Think campaign might be increasing anxiety levels in people engaging in the night-time economy, and in effect increasing violence rates (Vasterman, 2005; Hall et al., 1978). That is, rather than offering practical solutions to avoid or defuse potentially dangerous situations, the Just Think campaign might instead incite fear through sensationalising worst-case scenarios of violence in the NTE. This could conceivably contribute to a night-time environment in which violence is expected, and in turn make patrons more ready for violence, and more prone to interpret non-aggressive cues as the contrary (Borders et al., 2007; Leonard et al., 2003; Quigley and Leonard, 2006). This could also lead to stronger, more violent responses to mild aggression (as is common in crowded alcohol-filled environments) because of fear of retribution (Graham and Homel, 2008). Alternatively, the use of the Just Think campaign may have resulted in a promotion of licensed premises as safe venues to frequent, leading to an increase in patronage. An increase in patronage may, in turn, lead to increased violence simply because of the greater density of people within licensed venues. Lastly, the Just Think campaign promotes drinking wisely. Given the presence of a culture within Geelong that advocates drinking to excess, it may be that people are unaware of what drinking 'wisely' constitutes. Therefore, it may be that patrons are not significantly reducing their alcohol consumption as a consequence of the Just Think campaign, and consequently alcoholrelated assaults are not reduced.

Finally, it is also worth noting the different trends since 2008 between ED data and police arrest data, with ED data indicating a steady increase in assault rates and police data showing a decline in assault rates during 2008. It is possible strategies to reduce alcohol-related harms around night-time environments have increased in the city centre, more people will turn to drinking at home or going to suburban licensed venues, but this requires more detailed data than available in Victoria.

\section{Limitations}

There are a number of limitations to this study. Firstly, it should be noted that both the ED-data and police-data most likely underestimate the actual frequencies of alcohol-related assaults and aggression. This assumption is based primarily on the reality that injuries sustained as a result of alcohol intoxication do not always require medical attention and are seldom reported to the police. Such cases would therefore not be represented in either data-set. Another related issue pertains to the fact that ED-data is recorded by medical staff whose main objective is patient assessment and immediate treatment, rather than noting any alcohol-involvement. On the other hand, assaults recorded by Victoria Police also rely, at least partially, on policing activities and can be dependent on where resources are targeted. For these reasons, it seems likely that a substantial proportion of alcohol-related cases go undetected. The lack of ED and Victoria Police cases also limits the power of the regression analysis in the current study.

Secondly, while the data forming the basis for the study help considerably in understanding the current and past situation in relation to alcohol-related violence in Geelong, there are other equally important information sources which are needed to provide a more complete and nuanced description of this problem. For example, ambulance records would be invaluable in providing insight into the instances of alcohol-related violence, which are intercepted and resolved on the street rather than in triage. Further, there are some problems related to studying a smaller city such as Geelong, as the number of cases occurring tends to limit the analyses which can be used. Most importantly, none of the measures directly address alcohol consumption levels beyond licensed venues, and yet the proportion of alcohol sales in the community is dominated by bottle-shop (or off-premises) sales. As alcohol consumption per se remains the main identifiable and actionable, element of violence throughout the community, these findings suggest that measures which reduce consumption outside licensed venues also warrant further investment and investigation.

Consideration should also be given to the fact that the interventions under scrutiny generally require some level of public participation to facilitate success. For example, the Just Think campaign is based on the notion of change in attitude towards alcohol-related violence through public awareness of the problem. This type of strategy thus requires time to gain momentum and to make an impact - perhaps more time than what was available at the time of datacollection for this study. Lastly, the current study lacks a control area for comparison to more fully investigate the 
effect of the studied internventions on alochol-related assualt rates.

\section{CONCLUSION}

In summary, the interventions implemented in Geelong do not appear to be associated with any reductions in alcohol-related harm. Of note is the increase, rather than a decrease, in alcohol-related assault rates after the implementation of the alcohol industry funded 'Just Think' social marketing campaign. The somewhat ad-hoc nature of the implementation of these measures, along with the overwhelming message regarding alcohol in Australia still being one of consumption until intoxication (Room, 1988), combine to suggest that these trends will continue without measures to reduce whole-of-community alcohol consumption such as reducing the availability of alcohol (restricting venue numbers and trading hours), access to alcohol (through increased price and minimum purchase age) and alcohol advertising (Babor et al., 2010).

\section{ACKNOWLEDGEMENTS}

Special thanks to Inspector Bill Mathers. This study was funded by the Australian Drug Foundation, VicHealth and the Transport Accident Commission (TAC). Thanks to: Lisa Armstrong Rowe (City of Greater Geelong), Darren Holroyd, Mario Gregorio, Ross Arblaster (Barwon Health), Bronwen Allsop (Barwon Health), Dr Jane Mallick, Sergeant Bob Pupavac, Dr Tom Callaly (Barwon Health), Inspector Barry Malloch, Superintendent Peter O'Neill, Inspector Carl Peers, Kirilee Tilyard (NDLERF) and A/Prof Tanya Chikritzhs.

\section{CONFLICT OF INTEREST}

None Declared

\section{REFERENCES}

Abbey, A., \& Ortiz, L.G. (2008). Alcohol and sexual violence perpetration. [accessed 27 July 2009].

Abbey, A., Zawacki, T., Buck, P.O., Testa, M., Parks, K., Norris, J., Martin, S.E., Livingston, J.A., McAuslan, P., Clinton, A.M., Kennedy, C.L., George, W.H., Davis, K.C., \& Martell, J. (2002). How does alcohol contribute to sexual assault? Explanations from laboratory and survey data. Alcoholism: Clinical and Experimental Research $26,575-581$.

Agostinelli, G.,\& Grube, J.W. (2002). Alcohol counter-advertising and the media - A review of recent research. Alcohol Research \& Health 26, 15-21.

Anderson, P., Chisholm, D., \& Fuhr, D. (2009). Effectiveness and costeffectiveness of policies and programmes to reduce the harm caused by alcohol. The Lancet 373, 2234-2246.

Austin, E.W., Pinkleton, B. E., \& Fujioka, Y. (2000). The Role of Interpretation Processes and Parental Discussion in the Media's Effects on Adolescents' Use of Alcohol. Pediatrics 105, 9.

Babor, T., Caetano, R., Casswell, S., Edwards, G., Giesbrecht, N., Graham, K., Grube, J., Grunewald, P., Hill, L., Holder, H., Homel, R., Osterberg, E., Rehm J., Room, R., \& Rossow, I. (2003). Alcohol: No Ordinary Commodity - Research and Public Policy, Oxford: Oxford University Press.
Babor, T. (2010). Alcohol: No Ordinary Commodity - Research and Public Policy, Oxford: Oxford University Press.

Borders, A., Barnwell, S., \& Earleywine, M. (2007). Alcohol-aggression expectancies and dispositional rumination moderate the effect of alcohol consumption on alcohol-related aggression and hostility. Aggressive Behavior 33, 327-338.

Chikritzhs, T., \& Stockwell, T. (2002). The impact of later trading hours for australian public houses (hotels) on levels of violence. Journal of Studies on Alcohol 63, 591.

Collins, D.J., \& Lapsley, H.M. (2008). The costs of tobacco, alcohol and illicit drug abuse to Australian Society in 2004/05. Canberra: Australian Government.

Finney, A. (2004). Violence in the night-time economy: Key findings from the research. London, RS, United Kingdom: UK Home Office, 6.

Graham, K., \& Homel, R. (2008). Raising the Bar: Preventing aggression in and around bars, pubs and clubs, London: Willan.

Hall, S., Critcher, C., Jefferson, T., Clarke, J.N., \& Roberts, B. (1978) Policing the Crisis: Mugging, the State and Law and Order, London: Macmillan.

Hauritz, M., \& Homel, R. (1998). Reducing violence in licensed venues through community safety action projects: The Queensland. Contemporary Drug Problems 25, 511.

Indig, D., Copeland, J., Conigrave, K.M., \& Rotenko, I. (2008). Why are alcohol-related emergency department presentations underdetected? An exploratory study using nursing triage text. Drug and Alcohol Review 27, 584-590.

Ingemann-Hansen, O., \& Brink, O. (2004). City centre violence. Journal Of Clinical Forensic Medicine 11, 303-307.

Klostermann, K.C., \& Fals-Stewart, W. (2006). Intimate partner violence and alcohol use: Exploring the role of drinking in partner violence and its implications for intervention. Aggression \& Violent Behavior 11, 587-597.

Laslett, A., Matthews, S., \& Dietze, P. (2007). The Victorian Alcohol Statistics Handbook Volume 8: Alcohol use and related harm among young people across Victorian Local Government Areas 2006., Melbourne, Victoria: Turning Point Alcohol and Drug Centre for the Department of Human Services.

Leonard, K.E., Collins, R.L., \& Quigley, B.M. (2003). Alcohol consumption and the occurrence and severity of aggression: an event-based analysis of male to male barroom violence. Aggressive Behavior 29, 346-365.

Livingston, M. (2008). A longitudinal analysis of alcohol outlet density and assault. Alcoholism: Clinical and Experimental Research 32, 10741079.

Livingston, M., Chikritzhs, T., \& Room, R. (2007). Changing the density of alcohol outlets to reduce alcohol-related problems. Drug And Alcohol Review 26, 557-566.

Miller, P.G., Hall, W., West, R., Marsden, J., \& Darke, S. (2010). A renewed call for action on alcohol policy. Addiction 105, 767-768.

Quigley, B.M., \& Leonard, K.E. (2006). Alcohol expectancies and intoxicated aggression. Aggression and Violent Behavior 11, 484496.

Room, R. (1988). The dialectic of drinking in the Australian life: From the Rum corps to the wine column. Drug Alc Rev 7: 413-437.

Rowe, S., Wiggers, J., Wolfenden, L., Francis, J.L. (2010). Establishments licensed to serve alcohol and their contribution to police-recorded crime in australia: further opportunities for harm reduction. Journal of Studies on Alcohol and Drugs 71, 909-916.

Rumbold, G., Malpass, A., Lang, E., Cvetkovski, S., \& Kelly, W. (1998). Evaluation of the Geelong Local Industry Accord Final Report. Melbourne, Australia: Turning Point Alcohol and Drug Centre Inc.

Salcedo, L.J.A., \& Carvalho, A.M.P. (2005). Maltrato infantil por agresores bajo efecto del alcohol. Revista Latino-Americana de Enfermagem $13,827-835$

Vasterman, P.L.M. (2005). Media-Hype. European Journal of Communication 20, 508-530.

Victoria Police. (2011). Crime statistics 2010/2011.

Wallin, E., Andreasson, S., Stockwell, T. (2005). Effects of a Community Action Program on Problems Related to Alcohol Consumption at 
Licensed Premises. Preventing harmful substance use: The evidence base for policy and practice. New York, NY US: John Wiley \& Sons Ltd, 207-223.

Wiggers, J., Jauncey, M., Considine, R., Daly, J., Kingsland, M., Purss, K., Burrows, S., Nicholas, C., \& Waites, R.J. (2004). Strategies and outcomes in translating alcohol harm reduction research into practice: the Alcohol Linking Program. Drug \& Alcohol Review 23, 355-364.

(C) Miller et al.; Licensee Bentham Open.

This is an open access article licensed under the terms of the Creative Commons Attribution Non-Commercial License (http://creativecommons.org/licenses/by-nc/3.0/) which permits unrestricted, non-commercial use, distribution and reproduction in any medium, provided the work is properly cited. 